\title{
Extent of Use of Information and Communications Technology and Inventory Management in the Nigerian Brewery Industry
}

\author{
Olusegun Timothy Odesola ${ }^{1)^{*}}$, Grace Oluyemisi Akinola ${ }^{2)}$ \\ 1)2) Obafemi Awolowo University \\ Ile-Ife, Osun State, Nigeria. \\ ${ }^{1)}$ segunodesola@gmail.com, segunodesola@oauife.edu.ng \\ 2)gakinola2002@yahoo.com
}

Article history:

Received 3 August 2018 Revised 3 October 2018 Accepted 3 October 2018

Available online 28 October 2018

Keywords:

Stock

Inventory Control

ICT

ICT usage

ICT adoption

\section{Abstract}

This paper examined the extent of usage of Information and Communications Technology (ICT) for inventory management in the Nigerian brewery industry; investigated the level of adoption of ICT in the inventory management phases; and the effect of the extent of ICT usage on its adoption by firms in the industry. Primary data formed the methodology of the study. The analysis of data collected was done using descriptive (tables and percentages) and inferential statistics. The results showed that majority of the respondents were using ICT tools and its associated components in their inventory management. It was revealed that the extent of ICT usage had significant effect on its adoption for inventory management by firms in the industry. Based on these findings, the study concluded that ICT is fully deployed and adopted to a very great extent for inventory management in the Nigerian brewery industry and that its adoption and usage in the brewery industry was influenced by its extent of use. The study recommends that firms in the industry should make judicious use of the identified ICT usage by adopting ICT solutions for their operations to boost the efficiency and effectiveness of their operations.

\section{INTRODUCTION}

Inventory control has turn out to be a subject of attention for managers of businesses all over the world because of the strategic position of inventory among business assets needed for continued sustainability of businesses. Flourishing manufacturing settings without doubt regarded inventory control as the life-wire and backbone of their operations. Inventories are assets that are being conserved for future use by the industries. Inventory management can be described as methods or techniques put in place by an organization to manage its inventory items be it consumables, raw, spare parts, semi-finished (work-in-progress) and finished good, in a bid to minimize the costs of inventory, inventory costs, ensure smooth production processes as well as attain set goals and objectives of an organization. The deployment of ICT had imparted positively on the velocity of output as well as aiding virtually all sectors of human endeavors. Musa [1] defined ICT as a broad phrase that encompasses all highly developed technical know-how in operating and spreading the result of processed data. Hence, the deployment of ICT in business organizations, has imparted positively on the procedures and performance of businesses in Nigeria [2].

Kanaracus [3] reported that during global economic meltdown in 2008 that crippled many business outfits adversely all over the world, expenses incurred for the installation of software and hardware needed for varied business operations were soaring resulting in an increase in their budgetary provisions. $\mathrm{Vu}$ [4] submitted that the employment of computer-based solutions is capable of boosting organizations' effectiveness and its competitive edge by sustaining enhanced communication and relations with consumers as well as resulting in considerable reduction in production cost and enhanced firms' growth and outputs.

\footnotetext{
${ }^{*}$ Corresponding author
} 
Since inventory control has turn out to be a subject of worry in the management of business organizations over the world, management of assets plays an important role for the continued sustainability of organizations. Hence, in a bid to make inventories available at the appropriate place, exact time, right price and suitable size, organizations must design encouraging processes for keeping their assets [5]. This is because inventory items have constituted the most considerable proportion of the current assets; hence its control has turn out to be a critical success issue for businesses that want to remain in the competitive market.

Stock tracing of the modern inventory management procedures was distinguished by the incessant alert of the bar code being hammed at a sales point. In the olden days, keeping of inventory items involved the wholesaler writing down purchases or units sold at the close of a day's business. This can then be used to project into the potential needs of their businesses [6].

From the report of the firms producing beer in Africa, it was discovered that a vast majority of the citizenry are drinking beer to the extent that return on investments in the industry has continued to impact positively on the economies of the countries in the continent. In fact, the industry grows rapidly in the continent. Nigeria is getting a high percentage of investments of the industry because of her lager number of inhabitants and huge markets for the brewery products. This has resulted to influx of global investors investing heavily in the industry [7].

The extent of information and communications technology (ICT) deployment and usage for varied business transactions by multinational business organizations and in some cases small and medium scale enterprises in Nigeria has been on the increase in the last few decades. It is noteworthy that this wind of change did not exempt the Nigerian brewery industry that has to contend with large volume of inventories of varying types and sizes.

Akinola \& Odesola [8] discovered that ICT had no significant effect on inventory management of breweries in Nigeria. Such empirical study needs to be critically examined to ascertain the extent of ICT usage and deployment and its associated effects that gave rise to such findings in an age where ICT based systems dictate the activities of most organizations. From review of relevant literature, numerous studies have been conducted with varied outcomes on the effect of management of inventory or inventory control on organizational performance and financial performance of multinational organizations as well as small and medium scale enterprises. Much has not been done on the effect of ICT on inventory management vis-a-vis the extent of usage of ICT in the brewery industry for inventory management.

The study will answer the following questions; what is the extent of usage of ICT in the Nigerian Brewery industry for the management of inventory? what is the level of adoption of ICT in the inventory management phases? does the extent of use of ICT affects its adoption for inventory management in the industry?

Hypothesis for this paper was in null form. This is as follows:

$\mathbf{H}_{\mathbf{0}}$ : Adoption of ICT by firms in the Nigerian Brewery Industry does not depend on its extent of use for inventory management.

$\mathbf{H}_{\mathbf{1}}$ : Adoption of ICT by firms in the Nigerian Brewery Industry depends on its extent of use for inventory management.

\section{RELATED WORKS}

Today's businesses, public corporations, non-governmental organizations, higher institutions of learning, secondary schools, institutions and industries relied so heavily on the deployment and usage of ICTs for their operations either to lessen production expenses, have competitive advantage and maintain and sustain good customer relationship. Musa [1] portrayed ICT as an embodiment of all extremely sophisticated technologies deployed in manipulating and communicating the output of processed data. Musa further stated that, there are three vital components of ICT, which are information, data processing to obtain information and the communication of the output of the data processing via networks. There are many areas where ICT can be of help but in business organizations it can be deployed in the management of customer relationship, inventory, data, information system and communication. What can be called a comprehensive use of ICT for inventory management was presented by Prasanna [9]. The list include; bridging the cultural gap( ICT has helped to bond the cultural gap by helping people from different cultures to transact business, communicate, and allow them to exchange views and ideas, thus increasing awareness and reducing bias) with this inventory items can be gotten from any part of the world. Cost effectiveness can be achieved with the automation and deployment of ICT based solutions a significant percentage of expenses that are usually incurred during business operations especially inventory management are drastically reduced.

A related study conducted by Odesola \& Akinola [10] reported that data processing mode has significant effect on the performance of inventory management systems of firms in the Nigerian brewery industry. Primary data was sourced for the study that was conducted in the southwestern part of Nigeria. Both descriptive and inferential 
statistics were used to analyze the data. Although the sample size and data analysis methods were appropriate, it was discovered that the study did not disclose the extent of ICT usage and its associated effects on the adoption of ICT for inventory management of brewery firms in Nigeria. This study bridged the knowledge gap noticed in that study.

Owuor and Mwangi [10] conducted a study on effect of ICT on successful implementation of Vendor Managed Inventory (VMI) among Manufacturing Firms in Nakuru County, Kenya. The study assessed the factors determining successful implementation of VMI among manufacturing firms in Nakuru County. Despite the proof of value addition by the VMI technique to effective and efficient supply chain, there are few researches works on the topic. From the study it was revealed that most manufacturing firms especially in Kenya are yet to deploy and successfully employ the technique in enhancing their supply chain performance. The findings of the study showed that the range of factors of VMI implementation had a significant relationship with successful implementation of the strategy. The study also concluded that ICT is key to the successful implementation of VMI strategy. The study was conducted using Kenya manufacturing firms that have deployed VMI for their inventory management. The study did not examine the integration of VMI into inventory management because it was shown from the findings that only few of the firms are using ICT powered VMI. The authors were not specific as touching the measurement of the independent variable ICT and there is ambiguity in the questionnaire with respect to the objectives of the study.

The conceptual framework of the study is shown in Figure 1. The figure below shows the relationship between Forecasting/ Planning, Receiving raw materials/ work-in-progress, storage, Issuing of Finished goods, Issuing of work-in-progress and Inventory Management.

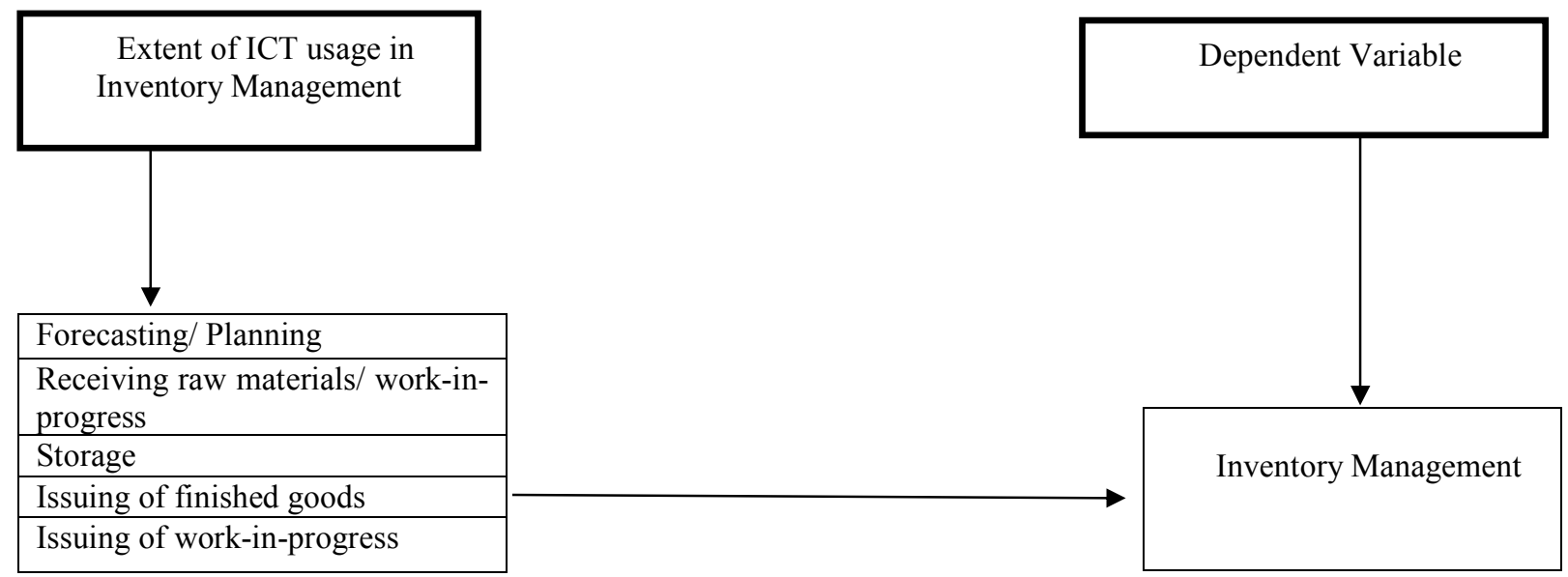

Fig. 1. Diagram showing the association between ICT, Revenue, Asset and Management of Inventory. Adopted from Odesola [11]

\section{METHODS}

Primary data were employed for this researchs. The primary data were gathered through administration of questionnaire. All staff of brewery companies quoted on the Nigerian Stock Exchange was the population for the study. The three leading brewery companies in Nigeria were purposively selected for the study and this represent three-quarter of quoted breweries in the facts sheet of the Nigerian Stock Exchange. These are International Breweries Plc, Guinness Nigeria Plc and Nigerian Breweries Plc. All staff of the selected breweries who are in care of management of inventory were also purposively selected. The data collected were analyzed using descriptive and differential statistics.

Theoretical Framework: Resource Dependency Theory suggests that management decisions are influenced by those who control critical resources, both internal and external to the firms [12]. The resource dependence perspective suggests that some functions may control resources that are critical to the success of the company and those functional areas can derive power from the control of these important resources [13]. The relative influence of a sub unit over another is a function of the resources the sub unit contributes [14]. This research was based on the above theory because companies in producing beers in the country have been investing heavily on installing computer based solutions in a special way in their operations in such a way that the ICT usage and deployment are controlling resources critical to the success of the beer business which grow rapidly in Nigeria and Africa. 


\section{RESULTS}

This study revealed that majority of the respondents $(91.0 \%)$ responded that the firms in the brewery industry adopted and used computer hardware devices (e.g. laptops, desktops, tablets, iPad, smartphones) to a very large extent, $2.2 \%$ adopted and used them to a large extent while $6.7 \%$ did same to a little extent. Also, $68.5 \%$ of the respondents indicated that the firms in the brewery industry adopted and used internet to a very large extent, $31.5 \%$ adopted and used it to a large extent. It was also discovered that $65.2 \%$ of the respondents responded that their firms adopted and used Inventory Management System (Enterprise Resource Planning) to a very large extent, 32.6\% adopted and used it to a large extent while $2.2 \%$ adopted and used it to a moderate extent. Meanwhile, $36.0 \%$ of the respondents indicated that their breweries adopted and used intranet to a very large extent, 33.7\% adopted and used it to a large extent, $1.1 \%$ did same to moderate extent, $9 \%$ adopted and used it to a Little extent while $20 . \%$ did same to a very little extent. Also, $60.0 \%$ of the respondents responded that their firms adopted and used scanner to a very large extent, $38.2 \%$ adopted and used it to a great extent while $1.1 \%$ did same to reasonable extent. $57.3 \%$ of the respondents responded that their firms adopted and used uninterrupted power supply to a very large extent, while $37.1 \%$ adopted and used it to a large extent while $5.6 \%$ did same to moderate extent (see Table 1 ).

TABLE 1

\begin{tabular}{|c|c|c|c|c|c|c|}
\hline ICT components & $\begin{array}{c}5 \\
\text { Very large } \\
\text { extent }(\%)\end{array}$ & $\begin{array}{c}4 \\
\text { Large } \\
\text { extent }(\%)\end{array}$ & $\begin{array}{c}3 \\
\text { Moderate } \\
\text { extent (\%) }\end{array}$ & $\begin{array}{c}2 \\
\text { Little } \\
\text { extent }(\%)\end{array}$ & $\begin{array}{c}1 \\
\text { Very little } \\
\text { extent }(\%)\end{array}$ & $\begin{array}{c}\text { Total } \\
\mathrm{N}=89(\%)\end{array}$ \\
\hline $\begin{array}{l}\text { Computer hardware devices (e.g. Laptops, desktops, } \\
\text { Tablets, iPad, smart phones) }\end{array}$ & 91.0 & 2.2 & 0.0 & 6.7 & 0.0 & 100.0 \\
\hline Internet & 68.5 & 31.5 & 0.0 & 0.0 & 0.0 & 100.0 \\
\hline $\begin{array}{l}\text { Inventory management system (enterprise resource } \\
\text { planning) }\end{array}$ & 65.2 & 32.6 & 2.2 & 0.0 & 0.0 & 100.0 \\
\hline Intranet & 36.0 & 33.7 & 1.1 & 9.0 & 20.2 & 100.0 \\
\hline Scanner & 60.0 & 38.2 & 1.1 & 0.0 & 0.0 & 100.0 \\
\hline Uninterrupted power supply (UPS) & 57.3 & 37.1 & 5.6 & 0.0 & 0.0 & 100.0 \\
\hline
\end{tabular}

TABLE 2

EXTENT TO WHICH THE BREWERY ADOPTED ICT IN THE PHASES OF THE INVENTORY MANAGEMENT [11]

\begin{tabular}{|c|c|c|c|c|c|c|}
\hline ICT components & $\begin{array}{c}5 \\
\text { Very large } \\
\text { extent }(\%) \\
\end{array}$ & \begin{tabular}{l}
\multicolumn{1}{c}{4} \\
Large \\
extent $(\%)$
\end{tabular} & \begin{tabular}{c}
\multicolumn{1}{c}{3} \\
Moderate \\
extent $(\%)$ \\
\end{tabular} & \begin{tabular}{l}
\multicolumn{2}{c}{2} \\
Little \\
extent (\%)
\end{tabular} & $\begin{array}{c}1 \\
\text { Very little } \\
\text { extent }(\%)\end{array}$ & $\begin{array}{l}\text { Total } \\
(\%)\end{array}$ \\
\hline Forecasting/ Planning & 68.5 & 30.3 & 1.1 & 0.0 & 0.0 & 100.0 \\
\hline Receiving raw materials/ work-in-progress & 89.9 & 10.0 & 0.0 & 0.0 & 0.0 & 100.0 \\
\hline Storage & 80.9 & 19.1 & 0.0 & 0.0 & 0.0 & 100.0 \\
\hline Issuing of finished goods & 36.0 & 48.3 & 7.9 & 0.0 & 0.0 & 100.0 \\
\hline Issuing of work-in-progress & 43.8 & 38.2 & 1.1 & 0.0 & 0.0 & 100.0 \\
\hline
\end{tabular}

Moreover, in determining the extent to which these companies adopted ICT in the phases of the inventory management it was discovered that majority of the respondents $(68.5 \%)$ indicated that their brewery adopted ICT to a very large extent in the forecasting/planning phase of inventory management, $30.3 \%$ adopted and used it to a large extent while $1.1 \%$ did same to a moderate extent.

From table 2, $89.9 \%$ of the respondents representing majority indicated that the brewery adopted ICT in the receiving raw materials/work-in-progress phase of inventory management to a very large extent while $10 \%$ did same to a large extent. It was also discovered that $80.9 \%$ of the respondents representing majority indicated that the brewery adopted ICT in the storage phase of inventory management to a very large extent while $19.1 \%$ adopted and used it to a large extent. In addition, it was discovered that $48.3 \%$ of the respondents representing majority of the respondents indicated that the brewery adopted ICT in the issuing of finished goods phase of inventory management to a large extent while $36 \%$ of the respondents responded that their firms adopted and used them to a very large extent and $7.9 \%$ did same to a moderate extent. Meanwhile $43.8 \%$ of the respondents representing majority indicated that the brewery adopted ICT in the issuing of work-in-progress phase of inventory management to a very large extent, $38.2 \%$ of the respondents adopted and used it to a very large extent and $1.1 \%$ did same to a moderate extent (see Table 2).

Does the extent of use of ICT affects its adoption for inventory management in the industry? For Hypothesis I: ICT adoption does not depend on its extent of usage by firms in the Nigerian Brewery Industry. Respondents were asked if they strongly agree, agree, undecided, disagree or strongly disagree with the notion that ICT adoption was as a result of the fact that it makes it easy to share information, aids managing supplier relationship, enhancing procurement and ordering processes, aids in collaborative planning and replenishment decisions, assists in 
warehousing and storage management (stock identification), accurate inventory information, improves service time per customer and aids customer relationship management. Their responses were presented in table 3.

TABLE 3

\begin{tabular}{ll} 
EFFECT OF ICT USAGE ON ITS ADOPTION FOR INVENTORY MANAGEMENT SYSTEM [11] \\
\hline \hline Options & Frequency \\
\hline Strongly Agree & 60 \\
Agree & 20 \\
Undecided & 4 \\
Disagree & 3 \\
Strongly Disagree & 2 \\
\hline Total & 89 \\
\hline \hline
\end{tabular}

Testing of the hypothesis

Using $\chi^{2}=\xi$ (Observed frequency - expected frequency) ${ }^{2}$

Expected frequency

Expected frequency $=\underline{60+20+4+3+2}=\underline{89}=17.8$

$5 \quad 5$

Calculated $\chi^{2}$ is 137.8 (see table 4) while the $\chi^{2}$ from the table is obtained by assuming $5 \%$ level of significance and using $\mathrm{M}=\mathrm{N}-1$ for degree of freedom, where $\mathrm{N}$ is the number of rows of the table for the chi-square. Here, $\mathrm{N}$ is 5 , therefore degree of freedom $(\mathrm{M})=5-1=4$. Therefore, the $\chi^{2}$ from the chi-square table is 9.488 . Since the computed $\chi^{2} ; 137.8$ is greater than 9.488 ; the study therefore reject the null hypothesis $\left(\mathrm{H}_{0}\right)$ and accept the alternate hypothesis $\left(\mathrm{H}_{1}\right)$. We conclude that extent of ICT use had significant effect on its adoption for inventory management by firms in the Nigerian Brewery Industry.

TABLE 4 CHI-SQUARE TABLE

\begin{tabular}{lrrrrr}
\hline \hline Responses & Observed (O) & Expected (E) & O-E & $(\mathrm{O}-\mathrm{E})^{2}$ & $\frac{(\mathrm{O}-\mathrm{E}) 2}{\mathrm{E}}$ \\
\hline Strongly Agreed & & & 17.8 & 42.2 & 1780.84 \\
Agree & 60 & 17.8 & 2.2 & 4.84 & 100.05 \\
Undecided & 20 & 17.8 & -13.8 & 190.44 & 10.70 \\
Disagreed & 4 & 17.8 & -14.8 & 219.04 & 12.31 \\
Strongly Disagreed & 3 & 17.8 & -15.8 & 249.64 & 14.02 \\
\hline Total & 2 & & & & $\mathbf{1 3 7 . 8}$ \\
\hline \hline
\end{tabular}

\section{DisCUSSION}

This study found that Breweries in Nigeria make use of Computer hardware devices (e.g. Laptops, Desktops, Tablets, iPad, Smart phones), Internet, Inventory Management System (Enterprise Resource Planning), Intranet, Scanner and Uninterrupted Power Supply (UPS) to a very large extent. From the results of the study, Breweries in Nigeria have adopted ICT in various phases of the inventory management cycle including Forecasting/ Planning, Receiving Raw Materials/ Work-in-progress, Storage, Issuing of Finished goods and Issuing of Work-in-progress to a very great extent. It was also revealed that the extent of ICT usage had a significantly positive effect on its adoption for inventory management by firms in the Nigerian brewery industry. The study discovered that the firms' adoption of ICT inventory management improved the inventory function (through accessibility of information from a centralized database), productivity and efficiency. The system facilitated checks and balances on all inventory transactions. It also showed that ICT aided in promoting consistent inventory management procedures, reducing on work-load as well as on improving the quality for the inventory function. These findings concur with the findings of previous studies carried out by Muthuri [15] and Momanyi \& Sanewu [16].

\section{CONCLUSIONS}

This study titled the extent of usage of information and communications technology and inventory management in the Brewery industry in Nigeria concluded that ICT is fully deployed and adopted to a very great extent for inventory management in the Nigerian Brewery industry. It is recommended that Breweries in Nigeria should invest more in modern technologies and adopt latest information and communications technology to integrate their 
inventory management and inventory management systems and enjoy the benefits from deploying an automated inventory management system for their inventory controls.

\section{REFERENCES}

[1] A. Musa, Foundation of Information and Communication Technology Course, Lagos: National Open University of Nigeria, 2013.

[2] O. K. Agbolade, "Information and communication technology and banks profitability in Nigeria," Australian Journal of Business and Management Research, vol. 1, no. 4, pp. 102-107, 2011.

[3] C. Kanaracus, "Gartner: Global IT spending growth stable," $2008 . \quad$ [Online]. Available: https://www.infoworld.com/article/2651482/techology-business/gartner--global-it-spending-growth-stable.html.

[4] K. Vu, "Embracing the ICT Revolution to Promote Economic Growth in Developing Countries: Policy Challenges," January 2004. [Online]. Available: https://sites.hks.harvard.edu/m-rcbg/ptep/khuongvu/Embracing\%20ICT-Policy\%20Challenges.pdf. [Accessed 10 January 2013].

[5] M. Itodo, Maji and Abdu, "Inventory Management as a Veritable Tool for Simulating Business Growth in Nigeria," Journal of Management Sciences, vol. 4, no. 1, pp. 64-77, 2010.

[6] R. Miller, Inventors Control: Theory and Practice, New Jersey: Prentice Hall, 2010.

[7] O. Olawale, Breweries Sector Report, Lagos: Meristem Securities Limited, 2014.

[8] G. O. Akinola and O. T. Odesola, "Information and Communications Technology and Inventory Management amongst Breweries in Nigeria," Journal of Information Systems Engineering and Business Intelligence, vol. 4, no. 1, pp. 39-45, 2018. http://dx.doi.org/10.20473/jisebi.4.1.39-45.

[9] P. Kumar, "Information Technology: Roles, Advantages and Disadvantages," International Journal of Advanced Research in Computer Science and Software Engineering, vol. 4, no. 6, pp. 1020-1024, 2014.

[10] O. T. Odesola and G. O. Akinola, "Impact of Data Processing Mode on Inventory Management System in the Nigerian Brewery Industry," Journal of Science, Technology, Mathematics and Education (JOSTMED), vol. 14, no. 1, pp. 56-67, 2018.

[11] O. J. Owuor and M. W. Mwangi, "Effect of ICT on Successful Implementation of Vendor Managed Inventory among Manufacturing Firms in Nakuru County, Kenya," International Journal of Science and Research, vol. 3, no. 5, pp. 1508-1513, 2014.

[12] O. T. Odesola, "Effect of Information and Communications Technology on Inventory Management in the Nigerian Brewery Industry," Obafemi Awolowo University, Ile-Ife, 2016.

[13] J. Pfeffer and G. R. Salancik, The External Control of Organizations: A Resource Dependence Perspective, New York: Harper \& Row, 1978.

[14] M. Tremblay, J. Côté and D. B. Balkin, "Explaining Sales Pay Strategy Using Agency, Transaction Cost and Resource Dependence Theories," The Journal of Management Studies, vol. 40, no. 7, pp. 1651-1682, 2003. https://doi.org/10.1111/1467-6486.00395.

[15] C. Homburg, J. P. Workman Jr and H. Krohmer, "Marketing's influence within the firm," Journal of Marketing, vol. 63, no. 2, pp. 1-17, 1999. http://dx.doi.org/10.2307/1251942.

[16] C. G. Muthuri, "Information And Communication Technology And Procurement Performance In Star Rated Hotels In Nairobi, Kenya," University of Nairobi, Nairobi, 2014.

[17] M. E. Mongare and S. E. Nasidai, "The Impact of Information Communication Technology on inventory control systems in transport organization: a case study of Kenya Ferry Services," European Journal of Logistics, vol. 2, no. 1, pp. 17-41, 2014. 